\title{
Médicos y pacientes. De números a personas
}

\author{
José Manuel de Toro Santos \\ Servicio de Medicina Interna. Complexo Hospitalario Universitario Ourensano
}

María es una anciana de 96 años, se le ve todavía con ganas de vivir, es delgada y de aspecto fibroso con la cara surcada de arrugas y manos de haber trabajado duro, hasta el momento llevaba su vida sencilla de forma autónoma, vivía en su casa con huerta que todavía ella misma cuidaba. La conozco tras su ingreso desde la urgencia del hospital por sufrir una neumonía que le produce una dificultad respiratoria que la incapacita. Tiene un hijo ya mayor que vive a $10 \mathrm{Km}$. de su casa y le visitaba una o dos veces a la semana. Me presento y me siento a su lado tendiéndole la mano, sus ojos me agradecen el gesto y me pregunta tras su mascarilla de oxígeno si se va a poner bien. He visto su historia y además de la neumonía se aprecia enfermedad pulmonar con posibles bronquiectasias bilaterales e insuficiencia renal. Durante los siguientes días tiene una ligera mejoría pero de nuevo empeora necesitando nuevos cambios en el tratamiento. Sus ojos van cambiando hacia la tristeza y sin que yo le diga nada ve que necesita ayuda a partir de ahora. Su hijo le explica que no puede vivir con ella todo el día y que tendrá que ingresar en una residencia. A partir de este momento María dejó de mirar con sus ojos verdes y lúcidos y solo mira el suelo de la habitación, cualquier información que le doy le da igual. En estas mismas fechas, con gran sobrecarga asistencial debido al exceso de número de pacientes y los recortes de profesionales en los últimos años, otro de los pacientes que atiendo se llama Antonio, tiene 92 años y había trabajado de carpintero toda su vida, ahora tenía una vida tranquila en su aldea, era viudo y vivía solo, compartiendo su vida diaria con los vecinos y amigos que le quedan todavía, tan mayores como él. Tiene una hija en Santander y un hijo en Francia. El día del ingreso los vecinos lo echan en falta y acuden a su casa encontrándole tirado en el suelo de la cocina con incapacidad para hablar y mover su mano y pierna derecha, la cara está desfigurada y quiere explicarles algo pero no logra expresarse. Tras llamar al 061 su médico se acerca a verlo y se traslada al hospital. Recuerdo que cuando empezaba mi profesión de médico, con frecuencia, eran los propios familiares y vecinos los que se encargaban de traer a los pacientes al hospital, las ambulancias eran escasas y tardaban en llegar; la implantación de este servicio ha mejorado indudablemente la atención a las personas. Al día siguiente recibo la llamada de la hija de Antonio interesándose por su padre e informándome que no podría venir por el momento, pues cuidaba a su hijo con discapacidad y no podía dejarle solo. Su hijo desde Francia llamó acto seguido y tras preguntarme por el estado de su padre y lo que se esperaba que ocurriera en las próximas horas, en que le expliqué que no podía aventurarle con seguridad lo que podría suceder, pues las personas que han llegado a los 90 con frecuencia nos sorprenden, me dijo que estaba consiguiendo un vuelo para venirse cuanto antes. Cuando llegó su hijo, Antonio estaba alerta con disfasia y visiblemente agitado por no poder expresarse, mantenía su hemiplejia fláccida y su hijo se abrazó a él nada más llegar, ambos soltaron lágrimas de cariño que reflejaban su propia historia vital. Al día siguiente se le comenzó a valorar la tolerancia oral a los alimentos y comenzó a comer purés. Su hijo venía con una semana de permiso en su trabajo y quería solucionar como y en donde podría cuidarse su padre tras este episodio. Un día, tras sufrir una broncoaspiración, despertó con disnea y fiebre y su estado empeoró. Los movimientos respiratorios le hacían ver a su hijo que su padre lo estaba pasando mal y al no mejorar me pidió que no quisiera que su padre sufriese. Le comenté que su padre tenía pautada morfina ante esta nueva situación para evitar la sensación de ahogo y que si el tratamiento no conseguía sus objetivos el siguiente paso sería iniciar una pauta de sedación. La aparición de un episodio de convulsiones inquietó todavía más a César, que así se llamaba el hijo y me pidió que lo hiciese cuanto antes.

Escribo esta editorial previo a la jubilación después de más de 40 años ejerciendo de médico en la sanidad pública. En la última sesión del servicio mis colegas me han regalado el libro de Henry Marsh', eminente neurocirujano inglés en el que relata las vivencias con aciertos y errores, las tomas de decisiones compartidas con sus pacientes y compañeros y que me sive de ayuda para reflexionar y recordar mi propia evolución y la de la especialidad de la medicina interna. Durante mi época de médico interno y residente pasábamos muchas horas en el hospital y llevábamos la mayoría de las tareas asistenciales con la supervisión de los adjuntos. 
Los pacientes que atendíamos eran en su mayoría menores de 65 años y gente joven con enfermedades agudas; los internistas nos dedicábamos a la hospitalización adquiriendo conocimientos en los métodos de diagnóstico y tratamiento de las enfermedades y vivimos el desarrollo de nuevas especialidades médicas y quirúrgicas. En los últimos 25 años, además de los grandes progresos en tecnología y sistemas informáticos, hemos asistido a un cambio progresivo en el tipo de pacientes que atendemos en los servicios de medicina interna en donde los pacientes de más de 75 años suponen las dos terceras partes en nuestro hospital $^{2}$ y las descompensaciones de las patologías crónicas respiratorias o cardiacas representan el mayor porcentaje de causas de hospitalización. El paciente con pluripatología y edad avanzada ha irrumpido en nuestra práctica diaria como el mayor exponente asistencial al que tenemos que atender y nos obliga a dar respuestas distintas basadas en sus necesidades personales, sociofamiliares y de una forma integrada con los demás profesionales del área de salud ${ }^{3}$. Las historias de María y Antonio son habituales y plantean las necesidades la reorientación del curriculum de internista en las áreas de cuidados del paciente pluripatológico y paciente frágil, con la valoración integral de los pacientes, formación en cuidados paliativos de pacientes crónicos ${ }^{4}$ y formas de trabajo compartido con los demás profesionales, pacientes y familiares a la hora de tomas de decisiones así como el desarrollo de habilidades comunicativas específicas para las personas mayores ${ }^{3,5,6}$. Muchos internistas se resisten a ver esta realidad permaneciendo en otras áreas de actuación en donde el arte del diagnóstico, brillante si es posible, y el tratamiento prima ante la acción sencilla y directa del cuidar de las personas. En este número de Galicia Clínica Núñez Viejo ${ }^{7}$ aborda las necesidades de formación en cuidados paliativos de los profesionales de medicina interna con la visión de dar atención paliativa a los pacientes con enfermedades crónicas más allá de la situación terminal y con la necesidad imperiosa de trabajar juntos con otras especialidades y equipos. También los trabajos de Mesquita de Oliveira et al. ${ }^{8}$ ejemplifican las características de pacientes de edad avanzada que ingresan por el servicio de urgencias y Romay-Lema et al. ${ }^{9}$ centra su atención en las hospitalizaciones de las personas centenarias, verdaderos libros de nuestra historia, que deberíamos mimar y de los que deberíamos aprender que han hecho para lograr esta supervivencia. Lo cierto es que nuestros hospitales se ven desbordados por los ingresos y reingresos de pacientes crónicos complejos y geriátricos frágiles a pesar de que la mayoría de estas personas se beneficiarían más de la integración de servicios sociales y sanitarios en el marco comunitario que de servicios especializados hospitalarios de elevada carga tecnológica ${ }^{10,11}$. El envejecimiento poblacional en Galicia y en concreto en las provincias de Lugo y Ourense alcanza cifras del 30\%, que es la prevista para Europa en el año 2050². Los profesionales, que conocemos la realidad diaria de las personas que atendemos en el ámbito de Atención primaria y hospitalización ${ }^{12,13}$, y los gestores, que se manejan con los números, debemos aproximarnos para trabajar juntos dentro del Programa de la Cronicidad y dar soluciones reales a los problemas de las personas y lograr que el sistema de salud sea sostenible.

\section{Bibliografía}

1. Ante todo no hagas daño. Henry Marsh. Editorial Salamandra. $8^{a}$ edición octubre de 2016.

2. de Toro Santos M, Gil Rodríguez S, Benito Torres C, Rozas Lozano P. La organización de la asistencia sanitaria a pacientes crónicos con pluripatología: La experiencia de Ourense. Galicia Clin 2012; 73 (Supl.1): S20-S26.

3. Ollero Baturone M, Orozco Beltrán D, Domingo Rico C, Román Sánchez P, López Soto A, Melguizo Jiménez M, et al. «Declaración de Sevilla». Conferencia nacional para la atención al paciente con enfermedades crónicas. Rev Clin Esp.2011; 211:604-6.

4. Jacob J. Strand, MD; Mihir M. Kamdar, MD; and Elise C. Carey, MD. Top 10 Things Palliative Care Clinicians Wished Everyone Knew About Palliative Care. Mayo Clin Proc 2013;88(8):859-865

5. Gual A, Oriol-Bosch A, Pardell H. El médico del futuro. Med Clin 2010; 134 (8):363368.

6. Cardellacha F, Vilardell M, Pujol R. La formación del médico del futuro: una revisión 10 años después. Med Clin. 2016; 147(7):313-315.

7. Núñez Viejo M. Los Cuidados Paliativos. Un nuevo reto para la Medicina Interna. Galicia Clínica.

8. Mesquita de Oliveira et al. Galicia Clinica

9. Romay-Lema E, Piñeiro-Fernández J, Ventura-Valcárcel P, Iñiguez-Vázquez I, Gómez-Méndez R, Rabuñal-Rey R, Monte-Secades R. Hospitalización en pacientes centenarios en Galicia en el periodo 2004-2013. Galicia clínica

10. Varela J. Las reformas necesarias en los hospitales: 10 recomendaciones para mejorar la eficiencia, la calidad y la efectividad. Med Clin. 2016; 146(3):133-137.

11. Future hospital: Caring for medical patients. A report from the Future Hospital Commission to the Royal College of Physicians. September 2013. London: Royal College of Physicians; 2013.

12. 25. W. Kahn M. Etiquette-Based Medicine. N Engl J Med.2008; 358; 19.

13. Larry R. Churchill and David Schenck. Healing Skills for Medical Practice. Ann Intern Med. 2008; 149: 720-724. 